\title{
EHMTI-0383. Spontaneous intracranial hypotension due to calcified micro-spurs perforating the dura - a case series
}

\author{
J Beck ${ }^{1 *}$, CT Ulrich ${ }^{1}$, J Gralla ${ }^{2}$, C Fung ${ }^{1}$, J Fichtner ${ }^{1}$, W Z'Graggen ${ }^{3}$, A Raabe ${ }^{1}$ \\ From 4th European Headache and Migraine Trust International Congress: EHMTIC 2014 \\ Copenhagen, Denmark. 18-21 September 2014
}

\section{Introduction}

Spontaneous intracranial hypotension $(\mathrm{SIH})$ is a rare but increasingly diagnosed condition. Low cerebrospinal fluid (CSF) pressure due to a dural leakage causes orthostatic headache. The nature, etiology, and location of the CSF leak itself are currently unknown and are thought to be spontaneous or idiopathic in most cases.

\section{Aim}

We present a case series with proven CSF leaks in which a systematic and meticulous search revealed dura-perforating micro-spurs as a cause of SIH.

\section{Methods}

A consecutive series of patients with symptoms of intracranial hypotension were evaluated for a systematic diagnostic work-up from February to August 2013. We performed a spine focused, stepwise escalating imaging set. If a CSF leak could be restricted, we performed microsurgical exploration under intraoperative electrophysiological monitoring of the presumed site of the CSF-leak.

\section{Results}

We identified 6 patients with SIH and imaging signs of spinal dural perforation. In 5 cases a calcified microspur extruding out of the disc space was identified perforated the dura and arachnoid and was the cause of CSF leak in all 5 cases. In one case a broad osteophyte had ripped the dura. All 5 micro spurs and one osteophyte were micro-surgically removed, the dura was sealed, and the CSF leak ceased immediately.

${ }^{1}$ Neurosurgery, Inselspital, Bern, Switzerland

Full list of author information is available at the end of the article

\section{Conclusions}

The etiology of the CSF leak in SIH remains obscure. Here we present 6 patients in which a systematic spinal work-up, including microsurgical exploration, revealed dura perforating micro spurs. The dura-perforating micro spurs were a frequent, definitive, and readily treatable cause of SIH.

No conflict of interest.

\section{Authors' details}

${ }^{1}$ Neurosurgery, Inselspital, Bern, Switzerland. ${ }^{2}$ Neuroradiology, Inselspital, Bern, Switzerland. ${ }^{3}$ Neurology, Inselspital, Bern, Switzerland.

Published: 18 September 2014

doi:10.1186/1129-2377-15-S1-J17

Cite this article as: Beck et al.: EHMTI-0383. Spontaneous intracranial

hypotension due to calcified micro-spurs perforating the dura - a case series. The Journal of Headache and Pain 2014 15(Suppl 1):J17.

Submit your manuscript to a SpringerOpen ${ }^{\odot}$ journal and benefit from:

- Convenient online submission

- Rigorous peer review

- Immediate publication on acceptance

- Open access: articles freely available online

- High visibility within the field

- Retaining the copyright to your article

Submit your next manuscript at $>$ springeropen.com (c) 2014 Beck et al; licensee Springer. This is an Open Access article distributed under the terms of the Creative Commons Attribution License (http://creativecommons.org/licenses/by/2.0), which permits unrestricted use, distribution, and reproduction in any medium, provided the original work is properly cited. 